- Note-

\title{
Effect of Operating Conditions of KrF Excimer Laser on Crystallinity of Deposits in LCVD from $\mathrm{Mo}(\mathrm{CO})_{6}$
}

\author{
Akio WatAnABE*, Yoji IMAI*, Kazuo OSATO, Masakazu MUKAIDA, \\ Ko-ichi SUGAwara, Harutoshi TAKEO, Tetsuya KameYAmA and Kenzo FUKudA
}

Received April 6, 1992 ; Accepted June 11, 1992

\section{INTRODUCTION}

It is well-recognized in the physical vapor deposition that the structure and morphology of deposits depend on the deposition rate $\left(D_{R}\right)$ and substrate temperature (Ts). These two parameters, however, are experimentally far from independent of each other in case of thermal CVD process because remarkable change of $D_{R}$ can be hardly brought about without the change of Ts. The mutual independence can be expected more definitely in the case of pulsed ultraviolet (UV) laser CVD(LCVD) because this process enables the change of $D_{R}$ without remarkable change of Ts and source gas-flow. From this point of view, the authors tried to investigate the effect of $D_{R}$ on the structure of deposit in CVD process by changing the operating conditions of laser. Molybdenum (Mo), a promising material as interconnects for very large scale integrated circuits, was used as a target material. Few results have been given on the structure of deposits by UV LCVD though several works reported that Mo thin flim containing carbon and oxygen can be deposited from $\mathrm{Mo}_{\mathrm{O}}(\mathrm{CO})_{6}{ }^{1-3}$ )

\section{EXPERIMENTAL}

The experimental setup for LCVD is shown schematically in Fig.1. A reaction cell with synthesized silica window was divided by two slits into three compartments. A substrate was placed in the third compartment at an angle of $60^{\circ}$ to the incident laser beam. About 0.1 Torr of sublimated gas from solid $\mathrm{Mo}(\mathrm{CO})_{6}$ placed in the glass vaporizer maintained at $300 \mathrm{~K}$ was directly introduced into this third compartment with the flow of $\mathrm{H}_{2}$ gas of $8.0 \mathrm{~cm}^{3} / \mathrm{min}(\mathrm{STP})$. The second compartment was cooled to dry ice temperature for catching the unreacted $\mathrm{Mo}(\mathrm{CO})_{B}$ gas by condensing onto the cell wall. The flow of $\mathrm{H}_{2}$ gas was introduced into the first compartment, which has an entrance window National chemical Laboratory for Industry (Higashi 1-1, Tsukuba, Ibaraki, 305) Key words: Excimer Laser CVD, Molybdenum for laser bealn, for preventing remaining Mo $(\mathrm{CO})_{6}$ from approaching to the window. Decomposition reaction by laser was thus mainly confined in the third compartment and decomposition on the window could be avoided. No intentional heating was applied to the substrate during the LCVD process, but the third compartment was kept at $315 \mathrm{~K}$ to warm up the gases. The total gas pressure was ca. 1.2 Torr. The sample was irradiated with unfocused laser beam from a Lumonics Model 460-SM-A Excimer Laser Equipment. A quartz plate was used as a substrate for deposits except for the deposits for composition analysis by Auger electron spectroscopy(AES), where a copper substrate was used to prevent the charge-up effect.

\section{RESULTS AND DISCUSSION}

Deposits with metallic luster were obtained on the irradiated spot by laser beam at various fluences $\left(F_{L}\right)$ and repetition rates $\left(R_{R}\right)$ of laser. The XRD pattern of the deposits showed the existence of metallic Mo and cubic Moz (JCPDS No.15-457). The crystallinity of the deposits, however, intensively depended on $R_{F}$ and $F_{L}$. The dependence of XRD patterns of the deposits on $R_{R}$ with the $F_{\mathrm{L}}=45 \mathrm{~mJ} / \mathrm{cm}^{2}$ is given in Fig. 2. The XRD patterns due to cubic MozC and metallic Mo are observable for the deposits obtained at lower $R_{R}$, while only halo-pattern are seen for that obtained at higher $R_{R}$. The dependence of the crystallinity on $F_{L}$ at the fixed $R_{R}$ of $10 \mathrm{~Hz}$ is given in Fig. 3. The crystal-

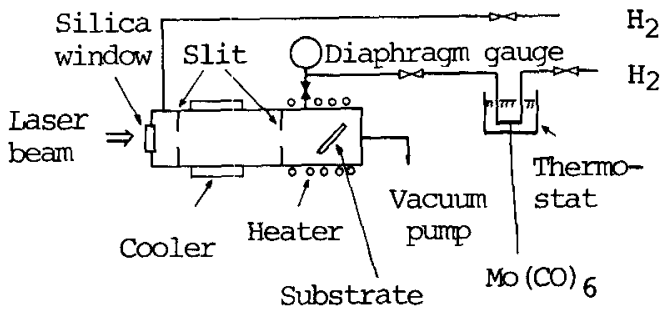

Fig.1 Schematic diagram of the experimental apparatus. 


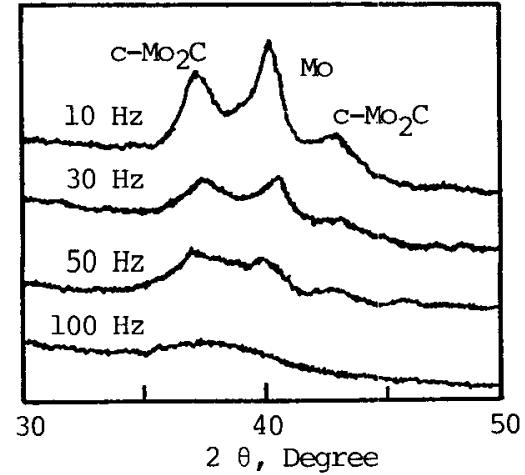

Fig. 2 XRD patterns of deposits obtained at laser fluence of $45 \mathrm{~mJ} / \mathrm{cm}^{2}$ at different repetition rates.

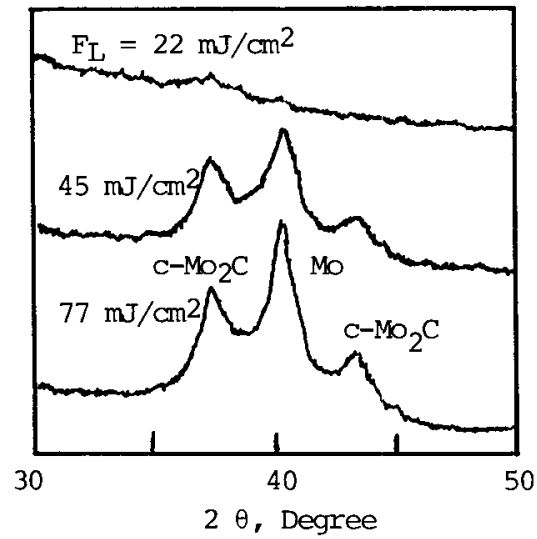

Fig. 3 XRD patterns of deposits obtained at repetition rate of $10 \mathrm{~Hz}$ at different laser fluences $\left(\mathrm{F}_{\mathrm{L}}\right)$.

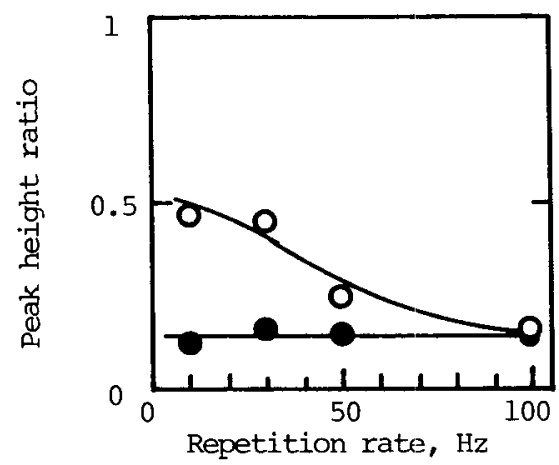

Fig. 4 Plots of peak height ratio of carbon (KLL, 272eV) to Mo (MNN, 187eV) ( ) and oxygen (KLL, 503eV) to Mo (MNN, 187eV) ( ) of deposit against repetition rate. linity tends to increase with $F_{L}$. Generally, the deposit was high in crystallinity when $F_{L}$ was high and $R_{R}$ of pulse was low. In order to explain these results, the effects of several factors known to affect the crystallinity of the deposit were discussed.

First, temperature effect was considered since Ts generally favors to better crystallinity of the deposit. Ts measured by conventional thermocouple at $F_{\mathrm{L}}=45 \mathrm{~mJ} / \mathrm{cm}^{2}$ were found to be $420 \mathrm{~K}$ and $320 \mathrm{~K}$ at $100 \mathrm{~Hz}$ and $10 \mathrm{~Hz}$, respectively. As expected, Ts rose with $R_{R}$. However, the effect of $R_{R}$ on crystallinity shown by Fig.2 was contrary to the speculation.

Secondly, it is also expected that a deposit will be poorly crystallized when the extent of decomposition of sample per pulse is small because of the insufficient density of nuclei over the critical nucleus size for the crystal growth. This effect can result in the production of quasi-amorphous deposits at higher $R_{R}$ if the diffusion rate of $\mathrm{Mo}(\mathrm{CO})_{\mathrm{S}}$ from the ambient gas into the laser beam was too small to supply sufficient amount to react. However, $D_{R}$ per pulse were found to be nearly the same for those obtained at $R_{R}$ of 10 and $100 \mathrm{~Hz} \quad(0.07$ and 0.05 $\mathrm{nm} / \mathrm{pulse}$ for 10 and $100 \mathrm{~Hz}$, respectively).

Another factor which may affect the crystallinity of deposits is the composition of deposits. It is known that the amorphous structure of metallic materials tend to be obtained when more quantity of nonmetallic elements is included ${ }^{4}$, because of the increase in the covalent bonding character. The result of the elemental analysis by AES of the deposit obtained is shown in Fig.4. As seen from the figure carbon content of deposit is independent of $R_{R}$, but oxygen content decreases with increasing $R_{R}$. The understanding how the oxygen content is influenced by the experimental condition is difficult because of the background contamination from airs ${ }^{5}$, but the results are in conflict with above assumption.

Since above three factors failed to $\mathrm{ex}-$ plain the results shown in Fig. 2, most probable explanation would be a slow rate of crystal growth on the surface of the substrate compared to the photolysis rate of Mo $(\mathrm{CO})_{B}$ at higher $\mathrm{R}_{\mathrm{R}}$. In the previous paper c), we have proposed the reaction scheme to explain the results on the rate of gas phase decomposition of Mo( $\mathrm{CO})_{0}$ by $\mathrm{KrF}$ excimer laser. The considered intermediates, formed by photolytic reaction of $\mathrm{Mo}(\mathrm{CO}) \mathrm{s}$, would not be large enough to be recognized 
as a crystal and re-ordering on the surface of the substrate would be required to form crystalline structure. The time required for this re-ordering seems to be of the order of time interval between successive laser pulses used in this experiment. As far as we know, this is the first observation of the effect of $R_{R}$ of pulse on the crystallinity of the deposit in LCVD experiments.

\section{References}

1)R.Solanki, P.K. Boyer, and G.J.Collins, Appl. Phys. Lett., 41, 1048 (1982).
2)P.K.Flynn, J.J.Steinfeld, and D.H.Sethi, J. Appl. Phys., 59, 3914 (1986).

3)N.S.Gluck, G.J.Wolga, C.E.Bartosch, and W.Ho. Z.Ying, J. Appl. Phys., 61, 998 (1987). 4)P.H.Shingu, R.Suzuki, and K.N.Ishihara, Kotai Butsuri, 20, 593 (1985).

5)K.A.Singmaster, F.A.Houle, and R.J.Wilson, Appl. Phys. Lett., 53, 1048 (1988).

6)A.Watanabe, Y. Inai, K. Osato, K.Sugawara, H.Takeo, T.Kameyama, and K.Fukuda, Denki Kagaku, 59, 1050 (1991). 